\title{
The Effect of Mass Ratio and Air Damper Characteristics on the Resonant Response of an Air Damped Dynamic Vibration Absorber
}

\author{
Ranjit G. Todkar ${ }^{1}$, Shridhar G. Joshi \\ ${ }^{1}$ Department of Mechanical Engineering, P.V.P. Institute of Technology, Budhagaon, Sangli, India \\ ${ }^{2}$ Department of Mechanical Engineering, Walchand College of Engineering, Sangli, India \\ E-mail: rgtodkar@gmail.com \\ Received October 21, 2011; revised November 25, 2011; accepted November 12, 2011
}

\begin{abstract}
In this paper, it is shown that, a road vehicle 2DOF air damped quarter-car suspension system can conveniently be transformed into a $2 \mathrm{DOF}$ air damped vibrating system representing an air damped dynamic vibration absorber (DVA) with an appropriate change in the ratio $\mu$ of the main mass and the absorber mass i.e. when mass ratio $\mu>>1$. Also the effect of variation of the mass ratio, air damping ratio and air spring rate ratio, on the motion transmissibility at the resonant frequency of the main mass of the DVA has been discussed. It is shown that, as the air damping ratio in the absorber system increases, there is a substantial decrease in the motion transmissibility of the main mass system where the air damper has been modeled as a Maxwell type. Optimal value of the air damping ratio for the minimum motion transmissibility of the main mass of the system has been determined. An experimental setup has been designed and developed with a control system to vary air pressure in the damper in the absorber system. The motion transmissibility characteristics of the main mass system have been obtained, and the optimal value of the air damping ratio has been determined for minimum motion transmissibility of the main mass of the system
\end{abstract}

Keywords: Air Damped Dynamic Vibration Absorber, Motion Transmissibility, Effect of Mass Ratio, Air Damper, Optimization

\section{Introduction}

Many real engineering systems such as, a road vehicle suspension system, a dynamic vibration absorber system, a vibration isolation system of machinery (where the floor supporting the machine is sufficiently flexible), a double centrifugal pendulum system etc., can be adequately represented as 2DOF vibrating systems [1]. As such, in this paper, a 2DOF air damped vibrating system representing a 2DOF air damped dynamic vibration absorber has been studied. In this case, the mass ratio $\mu$ i.e., ratio of the main mass $m_{2}$ to the auxiliary mass $m_{1}$ is greater than unity $(\mu>>1)$ and is in the range of 2.5 to 5.0 . Also the effect of variation of the mass ratio, air spring rate ratio and air damping ratio on the motion transmissibility of main mass has been discussed. It has been shown that, as the air damping ratio in the absorber system increases, there is a substantial decrease in the motion transmissibility of the main mass system in the neighborhood of resonant frequency for the case where the air damper is modeled as a Maxwell type [2,3]. Optimal value of the air damping ratio for the minimum transmissibility of the main mass system has been determined. An experimental setup has been designed with an air pressure control system for setting the appropriate value of air damping ratio in the system. The motion transmissibility characteristics of the main mass $m_{2}$ of the dynamic vibration absorber model have been obtained.

\section{Equations of Motion}

Equations of motion have been derived and are given respectively in Tables 1, 2 and $\mathbf{3}$ for the following [2],

1) A 2DOF dynamic vibration absorber system with system damping only and without air damper (Refer Figure 1 in Table 1), here after referred as Case 1.

2) A $2 \mathrm{DOF}$ air damped dynamic vibration absorber system with system damping and, Vogit type model for 
Table 1. A general 2DOF viciously damped vibrating system with system damping.

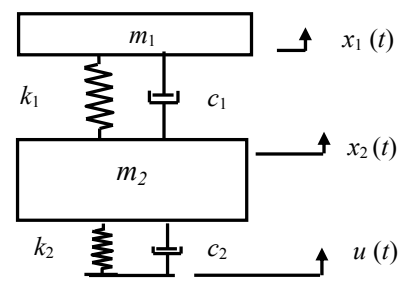

A general 2DOF vibrating system (Dynamic Vibration Absorber Model). $\mu>>1$.

Equations of motion

$$
\begin{aligned}
& m_{2} \ddot{x}_{2}=-k_{1}\left(x_{2}-x_{1}\right)-c_{1}\left(\dot{x}_{2}-\dot{x}_{1}\right)-k_{2}\left(x_{2}-u\right)-c_{2}\left(\dot{x}_{2}-\dot{u}\right) \\
& m_{1} \ddot{x}_{1}=-k_{1}\left(x_{1}-x_{2}\right)-c_{1}\left(\dot{x}_{1}-\dot{x}_{2}\right) \\
& \operatorname{Mt} 2=\frac{\mathrm{X}_{2}}{\mathrm{U}}=\left[\frac{\left[-A_{22} \lambda^{2}+A_{00}\right]^{2}+\left[A_{11} \lambda\right]^{2}}{\left[B_{4} \lambda^{4}-B_{2} \lambda^{2}+B_{0}\right]^{2}+\left[-B_{3} \lambda^{3}+B_{1} \lambda\right]^{2}}\right]^{\frac{1}{2}} \\
& \mathrm{Mt} 1=\frac{\mathrm{X}_{1}}{\mathrm{U}}=\left[\frac{\left[-A_{2} \lambda^{2}+A_{0}\right]^{2}+\left[A_{1} \lambda\right]^{2}}{\left[B_{4} \lambda^{4}-B_{2} \lambda^{2}+B_{0}\right]^{2}+\left[-B_{3} \lambda^{3}+B_{1} \lambda\right]^{2}}\right]^{\frac{1}{2}}
\end{aligned}
$$

where

$$
\begin{aligned}
& A_{22}=2 \zeta_{2}, A_{11}=v^{2}+4 \zeta_{1} \zeta_{2} v, A_{00}=2\left(\zeta_{1} v^{2}+\zeta_{2} v\right), \text { and } \\
& A_{2}=4 \zeta_{1} \zeta_{2} v, A_{1}=2 \zeta_{1} v^{2}, A_{1}=2 \zeta_{1} v^{2}, A_{0}=v^{2} \text { and } \\
& B_{4}=1, B_{3}=2\left(\zeta_{1}+\left(\zeta_{1} / \mu\right)+\zeta_{2} v\right), B_{2}=\left(1+(1 / \mu)+v^{2}\right), \\
& B_{1}=2\left(v \zeta_{2}+\zeta_{1} v^{2}\right), B_{0}=v^{2}
\end{aligned}
$$

air damper (Refer Figure 2 in Table 2), hereafter referred as Case 2.

3) A $2 \mathrm{DOF}$ air damped dynamic vibration absorber system with system damping and with Maxwell type model for air damper (Refer Figure 3 in Table 3), hereafter referred as Case 3.

\section{Motion Transmissibility}

Assuming the steady state solutions in the form $x_{1}=$ $\mathrm{Xe}^{\mathrm{jwt}}, x_{2}=\mathrm{X}_{2} e^{\mathrm{jwt}}$ and $y=\mathrm{Y} e^{\mathrm{jwt}}$ the base excitation as $u=$ $\mathrm{U} e^{j w t}$ and following the usual procedure of solution, the equations of motion have been solved and the expressions for the motion transmissibility Mt2 (for the main mass ) and Mt1 (for the auxiliary mass) have been obtained and are given respectively in Equations (3) and (4) for Case 1 in Table 1 and in Equations (7) and (8) for Case 2 in Table 2 and in Equations (12) and (13) in Table 3. [4].
Table 2. 2DOF Air damped vibrating system using an air damper (Vigot Model), with system damping coefficients $c_{1}$, $c_{2}$ and air damper characteristics i) air ddamping. Ratio $\zeta_{a}$ and ii) air spring rate ratio $k=\left(k_{a} / k_{1}\right)$,where $k_{1}=$ stiffness of auxiliary spring and $k_{a}=$ stiffness of air spring.

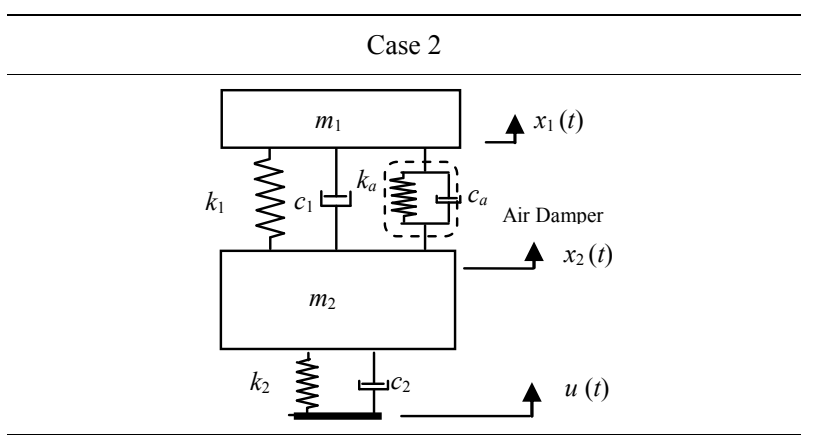

DOF air damped vibrating system using an air damper (Vigot Model). (Dynamic Vibration Absorber Model). $\mu \gg>1$.

Equations of motion

$$
\begin{aligned}
m_{2} \ddot{x}_{2}= & -\left(k_{1}+k_{a}\right)\left(x_{2}-x_{1}\right)-\left(c_{1}+c_{a}\right)\left(\dot{x}_{2}-\dot{x}_{1}\right) \\
& -k_{2}\left(x_{2}-u\right)-c_{2}\left(\dot{x}_{2}-\dot{u}\right) \\
m_{1} \ddot{x}_{1}= & -\left(k_{1}+k_{a}\right)\left(x_{1}-x_{2}\right)-\left(c_{1}+c_{a}\right)\left(\dot{x}_{1}-\dot{x}_{2}\right)
\end{aligned}
$$

$$
\mathrm{Mt} 2=\frac{\mathrm{X}_{2}}{\mathrm{U}}=\left[\frac{\left[-a_{22} \lambda^{2}+a_{00}\right]^{2}+\left[a_{11} \lambda\right]^{2}}{\left[b_{4} \lambda^{4}-b_{2} \lambda^{2}+b_{0}\right]^{2}+\left[-b_{3} \lambda^{3}+b_{1} \lambda\right]^{2}}\right]^{\frac{1}{2}}
$$

$$
\mathrm{Mt} 1=\frac{\mathrm{X}_{1}}{\mathrm{U}}=\left[\frac{\left[-a_{2} \lambda^{2}+a_{0}\right]^{2}+\left[a_{1} \lambda\right]^{2}}{\left[b_{4} \lambda^{4}-b_{2} \lambda^{2}+b_{0}\right]^{2}+\left[-b_{3} \lambda^{3}+b_{1} \lambda\right]^{2}}\right]^{\frac{1}{2}}
$$


Table 3. 2DOF air damped vibrating system using an air damper (Maxwell Model), with system damping coefficients $c_{1}, c_{2}$ and air damper characteristics air damping ratio $\zeta_{a}$ and air spring ratio $k=\left(k_{d} / k_{1}\right)$, where $k_{1}=$ stiffness of auxiliary spring and $k_{a}=$ stiffness of air spring.

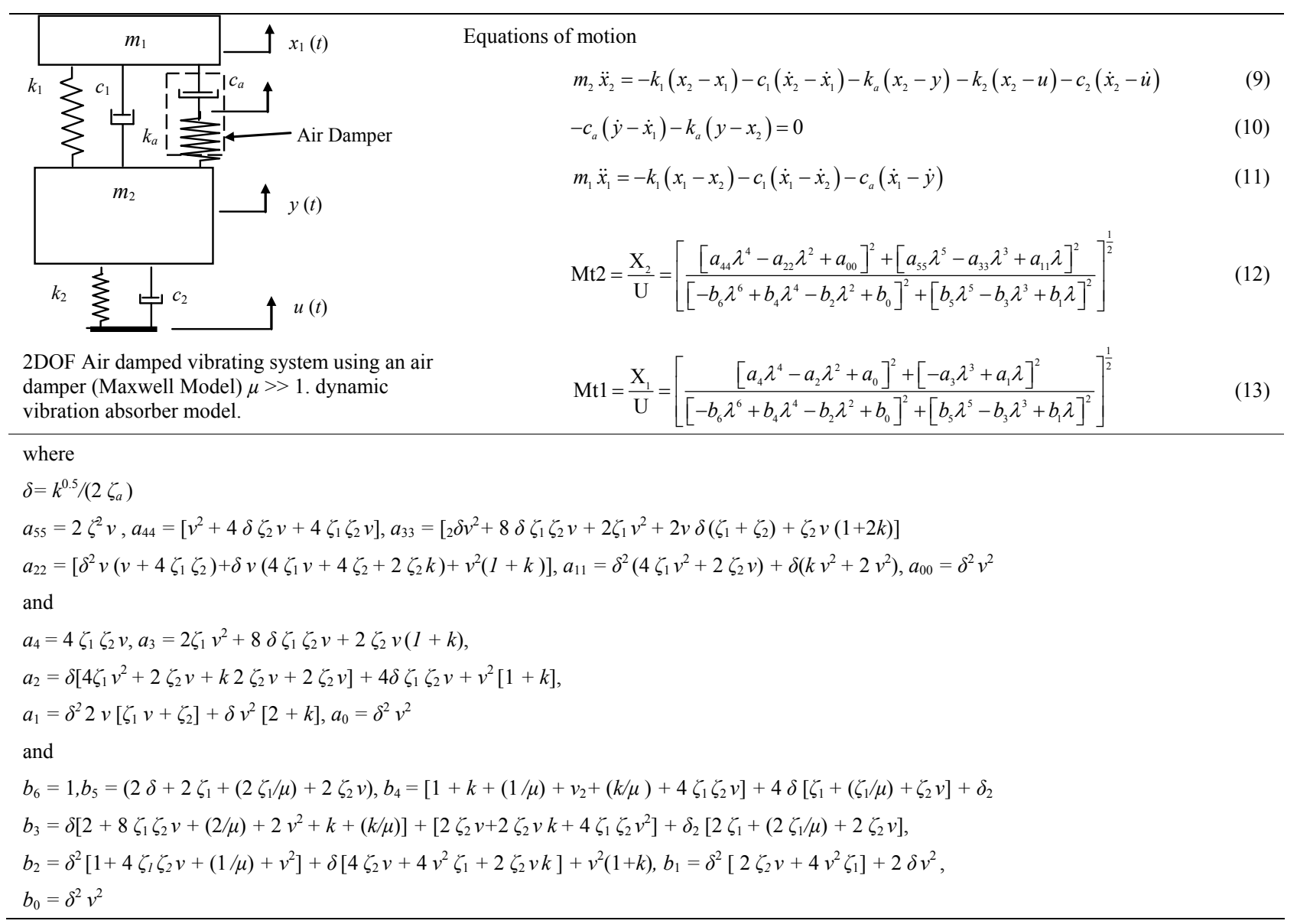

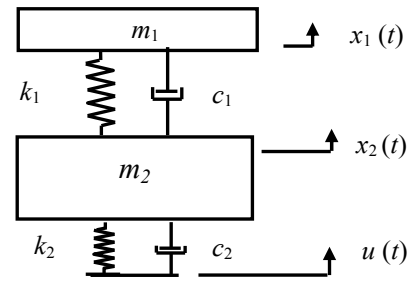

Figure 1. A general 2DOF vibrating system (dynamic vibration absorber model). $\mu>>1$.

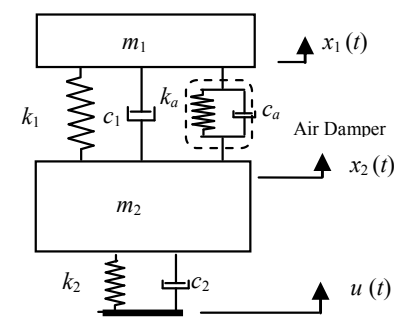

Figure 2. DOF air damped vibrating system using an air damper (vigot model). (dynamic vibration absorber model). $\mu$ $>1$.

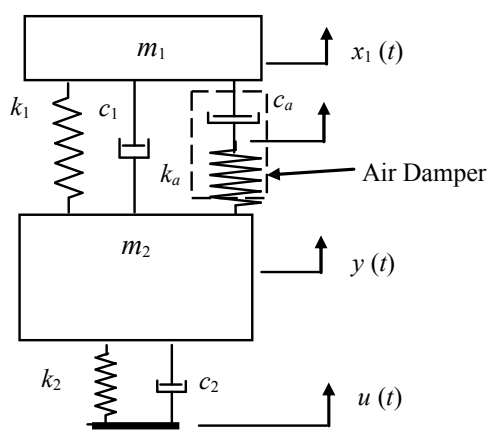

Figure 3. 2DOF air damped vibrating system using an air damper (maxwell model) $\mu>>1$. dynamic vibration absorber model.

\section{Motion Transmissibility Mt2 $(\mu>>1)$}

For the air damped dynamic vibration absorber system, mass ratio $\mu$ has been varied in the range of 2.5 to 5.0, where $\lambda$ is the ratio of excitation frequency $w$ to the undamped natural frequency $w_{l}$ of the system $\left.\left(m_{1}, k_{1}\right)\right)$, have 
been plotted for Case 1, Case 2 and Case 3. The peak values of Mt2 (at resonance) are given in Tables 4, 5 and 6 respectively.

\subsection{Effect of Variation of Mass Ratio $\mu$}

The values of $\mu$ are varied as $\mu=2.5, \mu=3.3$ and $\mu=5.0$ when $\zeta_{1}=0.1, \zeta_{2}=0, k=0.1$ and $\zeta_{a}=0.05$ with spring rate ratio $\left(k_{2} / k_{1}\right)$ as 6.49 . Table 4 gives respectively the peak values of Mt2 at resonant frequencies obtained for Case 1, Case 2 and Case 3. It is seen that, as the value of $\mu$ increases, there is no substantial change in the value of $\mathrm{Mt} 2$ at the first resonant frequencies for the case where the air damper is modeled as a Maxwell type. Figure 4, Figure 5 and Figure 6 show the corresponding Mt2 vs $\lambda$ plots.

Table 4. Peak values of Mt2 with $\zeta_{1}=0.100, \zeta_{2}=0.0, k=0.1$ and $\zeta_{a}=0.05$ and value of mass ratio $\mu$ is varied.

\begin{tabular}{|c|c|c|c|c|c|c|c|c|c|c|}
\hline \multirow{3}{*}{$\begin{array}{r}\text { Peak Valı } \\
\text { Mt2 }\end{array}$} & & \multicolumn{3}{|c|}{$\mu=2.5$} & \multicolumn{3}{|c|}{$\mu=3.3$} & \multicolumn{3}{|c|}{$\mu=5.0$} \\
\hline & ues of & \multirow{2}{*}{$\begin{array}{l}\text { With system } \\
\text { damping only } \\
\text { Case } 1\end{array}$} & \multicolumn{2}{|c|}{$\begin{array}{l}\text { Air damper } \\
\text { modeled as a }\end{array}$} & \multirow{2}{*}{$\begin{array}{l}\text { With system } \\
\text { damping only } \\
\text { Case } 1\end{array}$} & \multicolumn{2}{|c|}{$\begin{array}{l}\text { Air damper } \\
\text { modeled as a }\end{array}$} & \multirow{2}{*}{$\begin{array}{l}\text { With system } \\
\text { damping only } \\
\text { Case } 1\end{array}$} & \multicolumn{2}{|c|}{$\begin{array}{l}\text { Air damper } \\
\text { modeled as a }\end{array}$} \\
\hline & & & $\begin{array}{c}\text { Vigot } \\
\text { Model Case } 2\end{array}$ & $\begin{array}{c}\text { Maxwell } \\
\text { Model Case } 3\end{array}$ & & $\begin{array}{c}\text { Vigot } \\
\text { Model Case }\end{array}$ & $\begin{array}{c}\text { Maxwell } \\
\text { Model Case } 3\end{array}$ & & $\begin{array}{c}\text { Vigot } \\
\text { Model Case } 2\end{array}$ & $\begin{array}{c}\text { Maxwell } \\
\text { Model Case } 3\end{array}$ \\
\hline 1st peak & $\lambda$ & 0.91 & 0.920 & 1.01 & 0.91 & 0.92 & 1.0 & 0.87 & 0.88 & 1.01 \\
\hline \multirow{2}{*}{$\begin{array}{l}\text { 2nd } \\
\text { Peak }\end{array}$} & $\mathrm{Mt} 2$ & 4.295 & 7.42 & 4.3402 & 3.4503 & 5.8782 & 5.154 & 6.662 & 4.1069 & 1.428 \\
\hline & $\lambda$ & 1.76 & 1.79 & 1.64 & 1.76 & 1.78 & 1.64 & 1.3 & 1.35 & 1.35 \\
\hline
\end{tabular}

Table 5. Peak values of Mt2 with $\mu=3.3, \zeta_{1}=0.133, \zeta_{2}=0.0$ and $\zeta_{a}=0.05$ and value of spring rate ratio $k$ is varied.

\begin{tabular}{|c|c|c|c|c|c|c|c|c|c|c|}
\hline \multirow{3}{*}{\multicolumn{2}{|c|}{$\begin{array}{c}\text { Peak Values of } \\
\text { Mt2 }\end{array}$}} & \multicolumn{3}{|c|}{$k=0.075$} & \multicolumn{3}{|c|}{$k=0.100$} & \multicolumn{3}{|c|}{$k=0.150$} \\
\hline & & \multirow{2}{*}{$\begin{array}{l}\text { With system } \\
\text { damping only } \\
\text { Case } 1\end{array}$} & \multicolumn{2}{|c|}{$\begin{array}{l}\text { Air damper } \\
\text { modeled as a }\end{array}$} & \multirow{2}{*}{$\begin{array}{l}\text { With system } \\
\text { damping only } \\
\text { Case } 1\end{array}$} & \multicolumn{2}{|c|}{$\begin{array}{l}\text { Air damper } \\
\text { modeled as a }\end{array}$} & \multirow{2}{*}{$\begin{array}{c}\text { With system } \\
\text { damping only } \\
\text { Case } 1\end{array}$} & \multicolumn{2}{|c|}{$\begin{array}{l}\text { Air damper } \\
\text { modeled as a }\end{array}$} \\
\hline & & & $\begin{array}{c}\text { Vigot } \\
\text { Model Case } 2\end{array}$ & $\begin{array}{c}\text { Maxwell } \\
\text { Model Case } 3\end{array}$ & & $\begin{array}{c}\text { Vigot } \\
\text { Model Case }\end{array}$ & $\begin{array}{c}\text { Maxwell } \\
\text { Model Case } 3\end{array}$ & & $\begin{array}{c}\text { Vigot } \\
\text { Model Case } 2\end{array}$ & $\begin{array}{c}\text { Maxwell } \\
\text { Model Case } 3\end{array}$ \\
\hline \multirow{2}{*}{1 st peak } & $\mathrm{Mt} 2$ & 9.2 & 2.836 & 0.5698 & 9.2 & 2.90 & 0.6152 & 9.2 & 3.045 & 0.6872 \\
\hline & $\lambda$ & 0.90 & 0.91 & 1.00 & 0.90 & 0.91 & 1.00 & 0.90 & 0.93 & 1.01 \\
\hline \multirow{2}{*}{$\begin{array}{l}2 \mathrm{nd} \\
\text { peak }\end{array}$} & $\mathrm{Mt} 2$ & 4.357 & 5.244 & 2.535 & 4.357 & 5.09 & 2.87 & 4.357 & 3.49 & 4.81 \\
\hline & $\lambda$ & 1.53 & 1.57 & 1.48 & 1.53 & 1.57 & 1.49 & 1.53 & 1.51 & 1.59 \\
\hline
\end{tabular}

Table 6. Peak values of Mt2 with $\mu=3.3, \zeta_{1}=0.133, \zeta_{2}=0.0$ and $k=0.10$ and value of air damping ratio $\zeta_{a}$ is varied.

\begin{tabular}{|c|c|c|c|c|c|c|c|c|c|c|}
\hline \multirow{3}{*}{\multicolumn{2}{|c|}{$\begin{array}{l}\text { Peak Values of } \\
\text { Mt2 }\end{array}$}} & \multicolumn{3}{|c|}{$\zeta_{a}=0.025$} & \multicolumn{3}{|c|}{$\zeta_{a}=0.05$} & \multicolumn{3}{|c|}{$\zeta_{a}=0.075$} \\
\hline & & \multirow{2}{*}{$\begin{array}{l}\text { With system } \\
\text { damping only } \\
\text { Case } 1\end{array}$} & \multicolumn{2}{|c|}{$\begin{array}{l}\text { Air damper } \\
\text { modeled as a }\end{array}$} & \multirow{2}{*}{$\begin{array}{l}\text { With system } \\
\text { damping only } \\
\text { Case } 1\end{array}$} & \multicolumn{2}{|c|}{$\begin{array}{l}\text { Air damper } \\
\text { modeled as a }\end{array}$} & \multirow{2}{*}{$\begin{array}{l}\text { With system } \\
\text { damping only } \\
\text { Case } 1\end{array}$} & \multicolumn{2}{|c|}{$\begin{array}{l}\text { Air damper } \\
\text { modeled as a }\end{array}$} \\
\hline & & & $\begin{array}{r}\text { Vigot } \\
\text { Model Cas }\end{array}$ & $\begin{array}{c}\text { Maxwell } \\
\text { Model Case } 3\end{array}$ & & $\begin{array}{r}\text { Vigot } \\
\text { Model Cas }\end{array}$ & $\begin{array}{c}\text { Maxwell } \\
\text { Model Case } 3\end{array}$ & & $\begin{array}{c}\text { Vigot } \\
\text { Model Case } 2\end{array}$ & $\begin{array}{c}\text { Maxwell } \\
\text { Model Case } 3\end{array}$ \\
\hline \multirow{2}{*}{ 1st peak } & $\mathrm{Mt} 2$ & 9.2 & 3.077 & 0.8848 & 9.2 & 2.9 & 0.6152 & 9.2 & 2.752 & 0.5135 \\
\hline & $\lambda$ & 0.9 & 0.91 & 1.02 & 0.9 & 0.91 & 1.00 & 0.9 & 0.915 & 0.99 \\
\hline \multirow{2}{*}{$\begin{array}{l}2 \mathrm{nd} \\
\text { peak }\end{array}$} & Mt2 & 4.357 & 5.157 & 7.367 & 4.357 & 5.090 & 2.87 & 4.357 & 5.035 & 2.011 \\
\hline & $\lambda$ & 1.53 & 1.58 & 1.53 & 1.53 & 1.57 & 1.49 & 1.53 & 1.57 & 1.47 \\
\hline
\end{tabular}




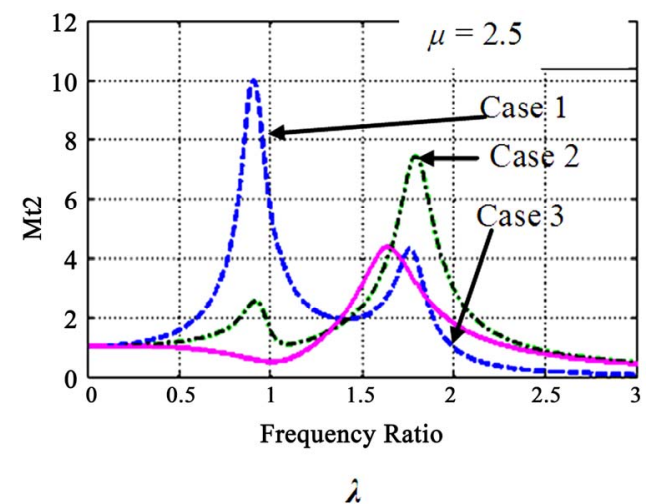

Figure 4. Mt2 vs $\lambda$ when $\zeta_{1}=0.1, \zeta_{2}=0, k=0.1$ and $\zeta_{a}=0.05$.

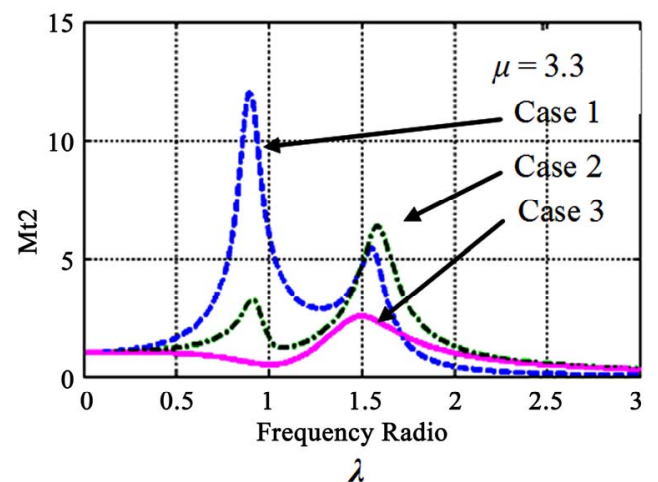

Figure 5. Mt2 vs $\lambda$ when $\zeta_{1}=0.1, \zeta_{2}=0, k=0.1$ and $\zeta_{a}=0.05$.

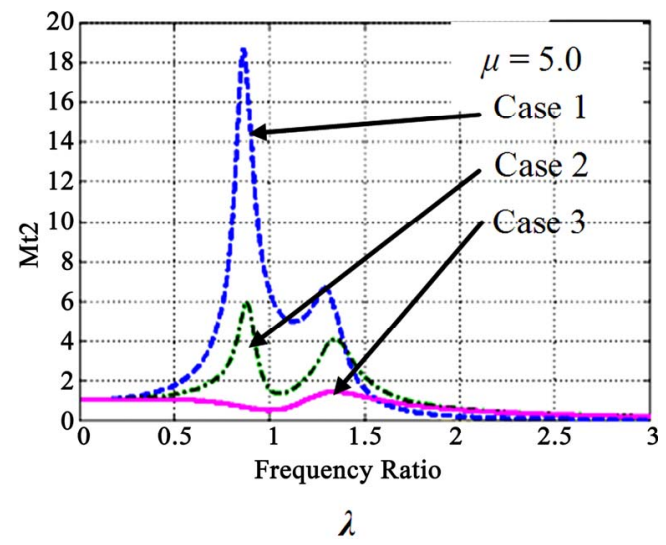

Figure 6. Mt2 vs $\lambda$ when $\zeta_{1}=0.1, \zeta_{2}=0, k=0.1$ and $\zeta_{a}=0.05$.

\subsection{Effect of Variation of Air Damper Spring Rate Ratio $k$}

The values of $k$ are varied as $k=0.075, k=0.10$ and $k=0.15$ when $\zeta_{1}=0.133, \zeta_{2}=0.0, \mu=3.3$ and $\zeta_{a}=0.05$ with spring rate ratio $\left(k_{2} / k_{1}\right)$ as 6.49 . Table 5 gives respectively the peak values of $\mathrm{Mt} 2$ at resonant frequencies obtained for Case 1, Case 2 and Case 3. It is seen that, as the value of air damper spring rate ratio $k$ increases, there is a small increase in the peak value of $\mathrm{Mt} 2$ at the resonant frequencies for the case where the air damper is modeled as a Maxwell type.

\subsection{Effect of Variation of Air Damping Ratio $\zeta_{a}$}

The values of air damping ratio $\zeta_{a}$ are varied as $\zeta_{a}=$ $0.025, \zeta_{a}=0.050$ and $\zeta_{a}=0.075$ when $\mu=3.3, \zeta_{1}=0.133$, $\zeta_{2}=0$ and $k=0.10$ with spring rate ratio $\left(k_{2} / k_{1}\right)$ as 6.49 . Table 6 gives respectively the peak values of $\mathrm{Mt} 2$ at resonant frequencies obtained for Case 1, Case 2 and Case 3. It is seen that, as the value of air damping ratio $\zeta_{a}$ increases there is a substantial decrease in the value of $\mathrm{Mt} 2$ at the resonant frequencies in the case where the air damper is modeled as a Maxwell type.

\section{Optimal Value $\zeta_{a o p t}$ of Air Damping Ratio $\zeta_{a}$}

The air damping is highly effective when the air damper was modeled as Maxwell type (Case 3). As such, a 2DOF air damped dynamic vibration absorber system for Case 3 is taken for optimization of air damping ratio $\zeta_{a}$ The equation of the motion transmissibility Mt2 (of the main mass m2) is given by Equation (13) of Table 3 for Case 3 when the air damper is modeled as a Maxwell type model [3]. The value of Mt2 is affected by the system parameters i.e. mass ratio $\mu$, system damping ratio $\zeta_{1}$ and the air damper characteristics 1) air spring rate ratio $k$ and 2) air damping ratio $\zeta_{a}$

For minimizing the value of $\mathrm{Mt} 2$, consider equation (13) for Mt2 is

$$
\begin{aligned}
& \operatorname{Mt} 2=\frac{X_{2}}{U} \\
= & {\left[\frac{\left[a_{44} \lambda^{4}-a_{22} \lambda^{2}+a_{00}\right]^{2}+\left[a_{55} \lambda^{5}-a_{33} \lambda^{3}+a_{11} \lambda\right]^{2}}{\left[-b_{6} \lambda^{6}+b_{4} \lambda^{4}-b_{2} \lambda^{2}+b_{0}\right]^{2}+\left[b_{5} \lambda^{5}-b_{3} \lambda^{3}+b_{1} \lambda\right]^{2}}\right]^{\frac{1}{2}} }
\end{aligned}
$$

(where constants $a_{44}, a_{33}, a_{22}, a_{11}, a_{00}, b_{6}, b_{5}, b_{4}, b_{3}, b_{2}, b_{1}$ and $b_{0}$ have been given in Table 3 ). The equation for Mt 2 is rearranged in terms of ascending powers of $\zeta_{a}$ as

$$
\begin{aligned}
& \mathrm{Mt} 2=\frac{\mathrm{X}_{2}}{\mathrm{U}} \\
& =\sqrt{\frac{\left(A_{4}\right) \zeta_{a}{ }^{4}+\left(A_{3}\right) \zeta_{a}{ }^{3}+\left(A_{2}\right) \zeta_{a}{ }^{2}+\left(A_{1}\right) \zeta_{a}+\left(A_{0}\right)}{\left(B_{4}\right) \zeta_{a}{ }^{4}+\left(B_{3}\right) \zeta_{a}{ }^{3}+\left(B_{2}\right) \zeta_{a}{ }^{2}+\left(B_{1}\right) \zeta_{a}+\left(B_{0}\right)}}
\end{aligned}
$$

where $A_{4}, A_{3}, A_{2}, A_{1}, A_{0}, B_{4}, B_{3}, B_{2}, B_{1}$ and $B_{0}$ are the constants containing system damping ratios $\zeta_{1}, \zeta_{2}, k, \mu, \lambda$ and $v$. The equation (14) for Mt2 is differentiated w.r.t. $\zeta_{a}$ and set equal to zero i.e. $\partial(\mathrm{Mt} 2) / \partial\left(\zeta_{a}\right)=0$, a polynomial in terms of $\zeta_{a}$ is obtained as

$$
\begin{aligned}
& h 7 \zeta_{a}^{7}+h 6 \zeta_{a}^{6}+h 5 \zeta_{a}^{5}+h 4 \zeta_{a}^{4} \\
& +h 3 \zeta_{a}^{3}+h 2 \zeta_{a}^{2}+h 1 \zeta_{a}+h 0=0
\end{aligned}
$$


where $h_{\mathrm{i}} \mathrm{s}(\mathrm{i}=0,1,2,3,4,5,6$ and 7) are the constant coefficients containing $\mu, \zeta_{1}, \zeta_{2}, k$ and $\lambda$. The expressions derived for this are very lengthy and have not been included in the body of the write-up. The optimal value $\zeta_{\text {aopt }}$ of $\zeta_{a}$ is obtained by solving the Equation (15) and with the optimal value thus obtained the values of Mt2 have been determined .

\subsection{Effect on Optimal $\zeta_{a o p t}$ and on Mt2 for Various Values of Air Spring Rate Ratio $k$}

The values of $\zeta_{\text {aopt }}$ for the air damper modeled as a Maxwell type model have been obtained for

1) $k=0.025, k=0.05, k=0.075$ and $k=0.1$ and the results are given in Table 7,

2) $k=0.200, k=0.3, k=0.4$ and $k=0.5$, the results are given in Table 8 and

3) $k=0.75, k=1, k=2$ and $k=3$, the results are given in Table 9 (Refer also Figure 7).

\subsection{Effect of Air Spring Rate Ratio $k$ on Optimal Value $\zeta_{a o p t}$ of $\zeta_{a}$ When $\mu=0.335, \zeta_{1}=0.133$, $\zeta_{2}=0.0$ and $\lambda=1$}

Figure 7 shows the effect $k$ on Optimal Value $\zeta_{\text {aopt }}$ of air damping ratio $\zeta_{a}$. From the results of analysis, it is seen that, as the value of $\zeta_{\text {aopt }}$ increases with the increase in air spring rate ratio $k$, the value of Mt2 increases. Figure 7 shows the variation of the value of Mt2 with $\zeta_{\text {aopt }}$ for increasing values of $k$.

\subsection{Effect of Variation of Mass Ratio $\mu$ on Optimal Value $\zeta_{a o p t}$ of $\zeta_{a}$}

Figure 8 shows the effect of variation of mass ratio $\mu$ on $\zeta_{\text {aot }}$ where air damper is modeled as a Maxwell type. The value of $\mu$ is varied as $\mu=2.5$ and $\mu=5.0$ when $\zeta_{1}=$ $0.133, \zeta_{2}=0, k=1$ and $\lambda=1$ with the spring ratio $\left(k_{2} / k_{1}\right)$

Table 7. Values of $\zeta_{\text {aopt }}$ when air spring rate ratio $k$ is varied.

\begin{tabular}{ccccc}
\hline Air Damper & \multicolumn{4}{c}{$\mu=3.3, \zeta_{1}=0.133, \zeta_{2}=0.0, \lambda=1$} \\
\cline { 2 - 5 } modeled as: & $k=0.025$ & $k=0.05$ & $k=0.075$ & $k=0.1$ \\
Maxwell type & $k=.3804$ & 0.3907 & 0.4004 & 0.4101 \\
\hline Mt2 (min) & 0.3804 & 0.10 & 0.12 & 0.13 \\
\hline$\zeta_{\text {aopt }}$ & 0.07 & &
\end{tabular}

Table 8. Values of $\zeta_{\text {aopt }}$ when air spring rate ratio $k$ is varied.

\begin{tabular}{|c|c|c|c|c|}
\hline \multirow{2}{*}{$\begin{array}{l}\text { Air Damper } \\
\text { modeled as: } \\
\text { Maxwell type }\end{array}$} & \multicolumn{4}{|c|}{$\mu=3.3, \zeta_{1}=0.133, \zeta_{2}=0.0, \lambda=1$} \\
\hline & $k=0.2$ & $k=0.3$ & $k=0.4$ & $k=0.5$ \\
\hline $\mathrm{Mt} 2(\min )$ & 0.4452 & 0.4754 & 0.5014 & 0.5236 \\
\hline$\zeta_{\text {aopt }}$ & 0.18 & 0.21 & 0.23 & 0.24 \\
\hline
\end{tabular}

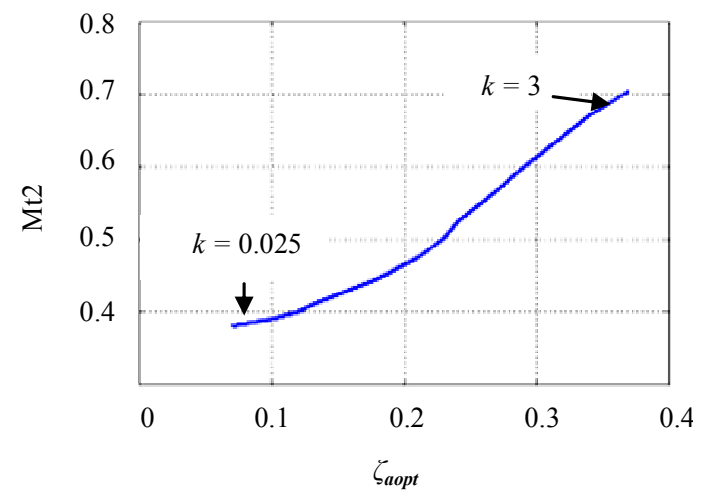

Figure 7. Mt2 vs $\zeta_{a}($ Effect of $k)$ for $k=0.025$ to 3.0.

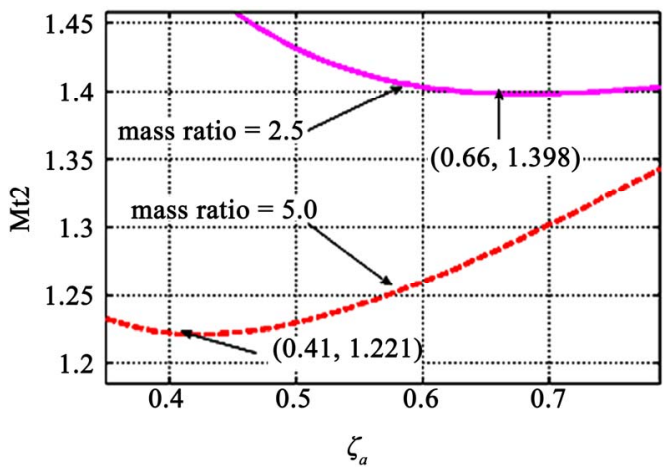

Figure 8. Mt2 vs $\zeta_{a}($ Effect of $\mu)$.

as 6.49 . It is seen that, as the value of $\mu$ increases, there is a significant reduction in the value of $\zeta_{a o p t}$ and there is also a substantial decrease in the minimum value of Mt2.

\section{Experimental Setup}

Figure 9 shows the experimental setup designed and developed for dynamic response analysis of the 2DOF air damped dynamic vibration absorber system (refer also Plate 1). The setup consists of a cam operated mechanism to provide sinusoidal base excitation .The necessary software has been developed to collect and process the dynamic displacements to obtain graphical plots of the input excitation $u(t)$ vs time and the main mass response motion $x_{2}(t)$ vs time. The system also incorporates the facility to control the operating air pressure in the system through a computer interfaced system as shown in Figure 9. The values of the main mass and auxiliary mass have been selected in accordance with values reported in the literature. The ratio of main mass $m_{2}$ to auxiliary $m_{1}$ is about 5 to 10 . The $2 \mathrm{DOF}$ air damped vibrating system data selected is as, main mass $m_{2}=6.0 \mathrm{~kg}$, auxiliary mass $m_{1}=0.815 \mathrm{~kg}$, auxiliary spring rate ratio $k_{1}=970$ $\mathrm{N} / \mathrm{M}$, the spring rate of the spring supporting the main mass $m_{2}$ is $k_{2}=6300 \mathrm{~N} / \mathrm{M}$ and mass ratio is $\mu=\left(m_{2} / m_{1}\right)$ is 7.36 . 


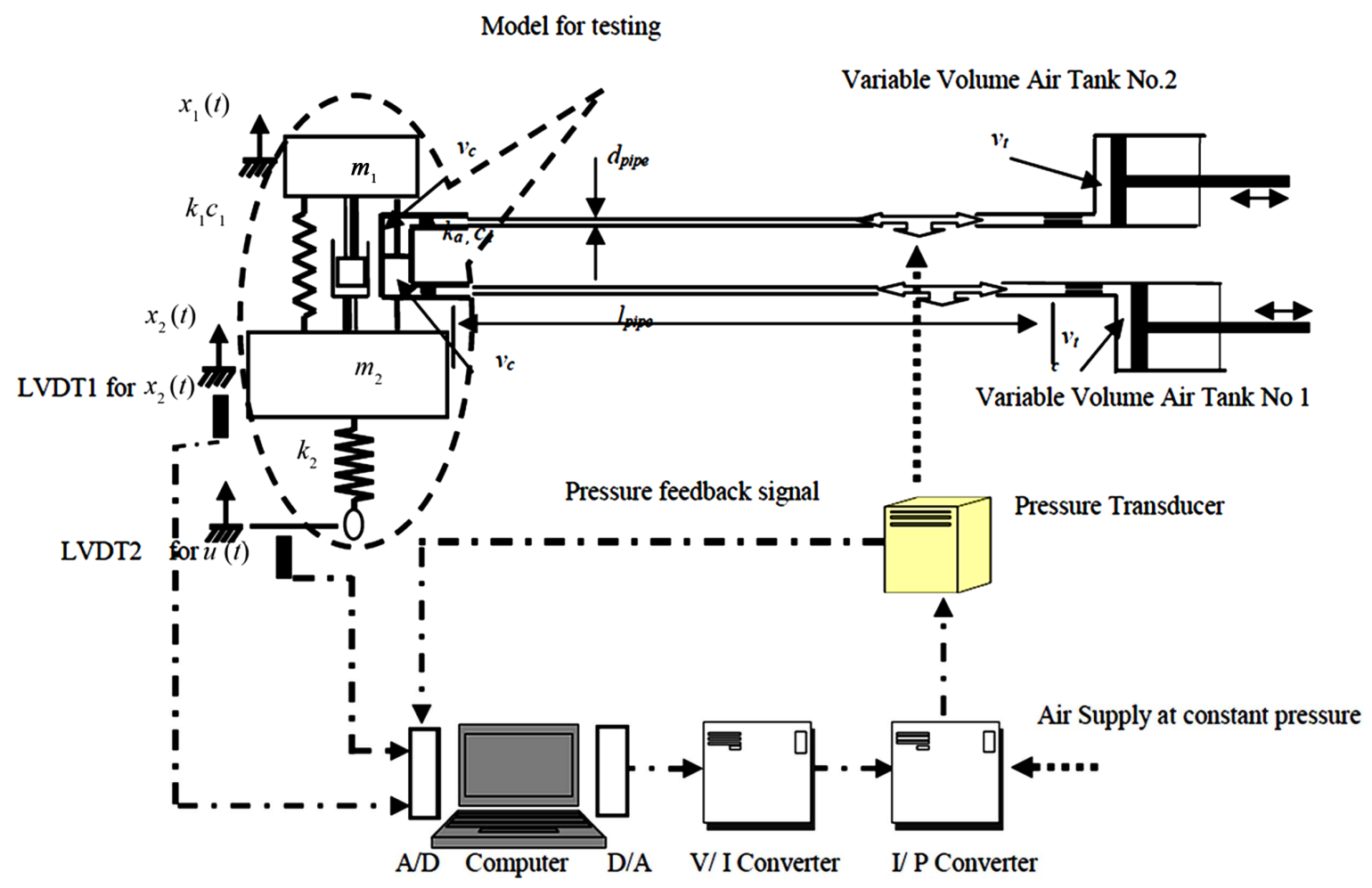

Figure 9. Experimental setup for 2DOF dynamic vibration absorber system $(\mu>>1)$.

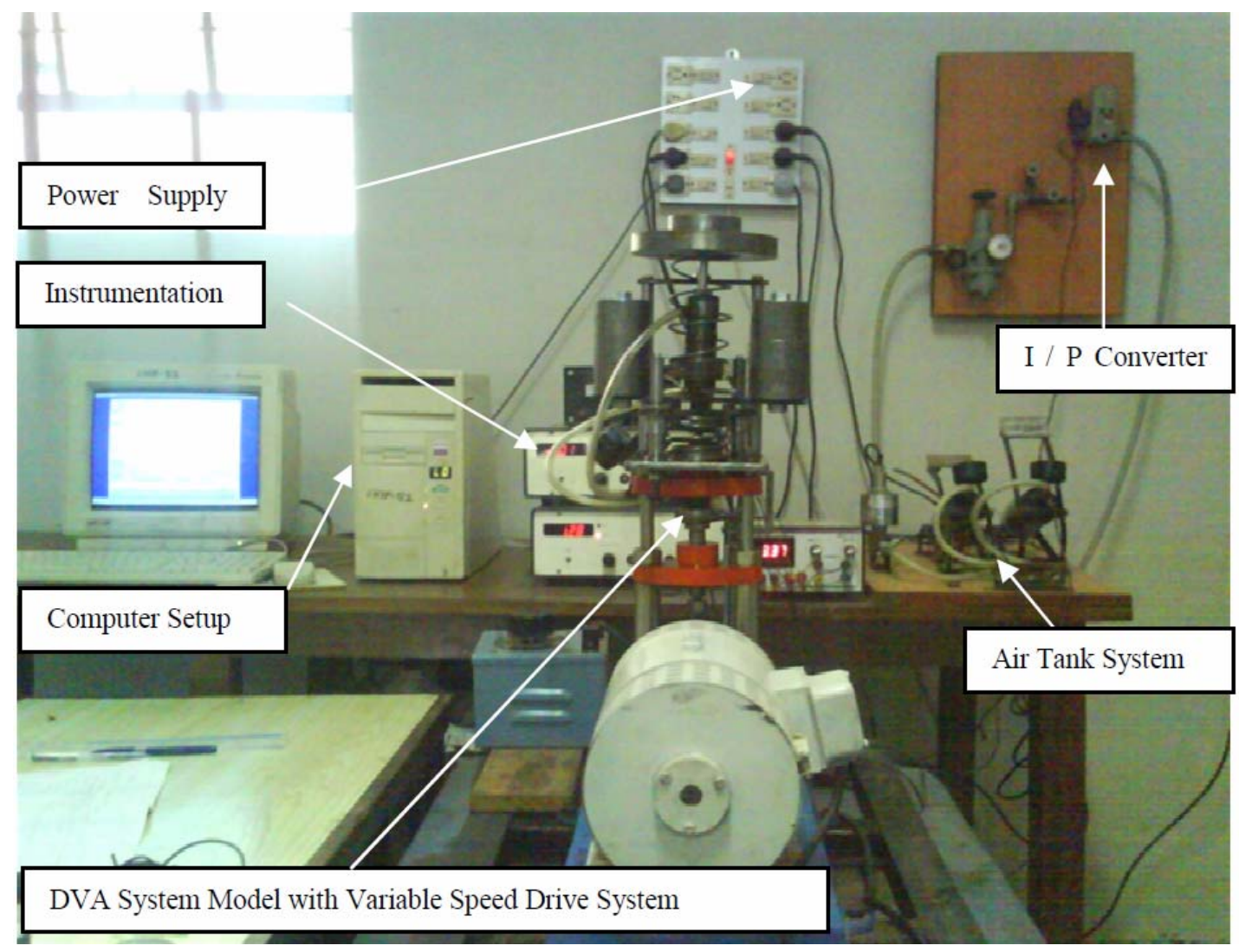

Plate 1. Experimental detup for an air damped 2DOF vibration absorber system. 


\subsection{Specifications of the Air Damper}

Using the approach of R.D.Cavanaugh [3] for the design of air damper, following relations have been developed $[4,5]$.

$$
\begin{aligned}
& \text { 1) } k_{a}=\left(2 n \mathrm{~s}^{2} / v_{c}\right)\left(p i / N_{t}\right) \\
& \text { 2) } \zeta_{a}=\mathrm{Q}_{1}\left[l_{\text {pipe }} /\left\{\left(p i / N_{t}\right)^{0.5}\left(d_{\text {pipe }}\right)^{4}\right\}\right]^{0.5}
\end{aligned}
$$

where $\mathrm{Q}_{1}=\left(128 \mathrm{~s} \mu_{o} / \pi\right)\left(v_{c} / 2 n m_{1}\right)$

Using these relations, a cylinder-piston and air-tank type air damper has been developed [3]. The specifications of the developed air damper are : piston diameter $d_{p}$ $=29.85 \mathrm{~mm}$ cylinder bore $d_{c}=30.00 \mathrm{~mm}$., piston rod diameter $d_{r}=10.00 \mathrm{~mm}$, piston length $l_{p}=13.0 \mathrm{~mm}$. and height of piston bottom from the cylinder bottom $h_{p}=$ $15.00 \mathrm{~mm}$ In the experimental investigation, the first step was to select the value of the air damping ratio $\zeta_{a}$ associated with the air spring rate ratio $k$ to be set and the corresponding set of capillary pipe dimensions like pipe diameter $d_{p i p e}$ and pipe length $l_{\text {pipe }}$. The ratio $(p i / N t)$, where $p i$ is the operating air pressure and $N t$ is the ratio $\left(v_{t} t v_{c}\right)$ is the basis for the selection of the air damping ratio $\zeta_{a}$ (also refer Figure 10 and Figure 11). The parameters $d_{p i p e}, l_{\text {pipe }}$ and the ratio ( $\left.p i / N t\right)$ have been varied to change the value of damping ratio $\zeta_{a}$ in the system.

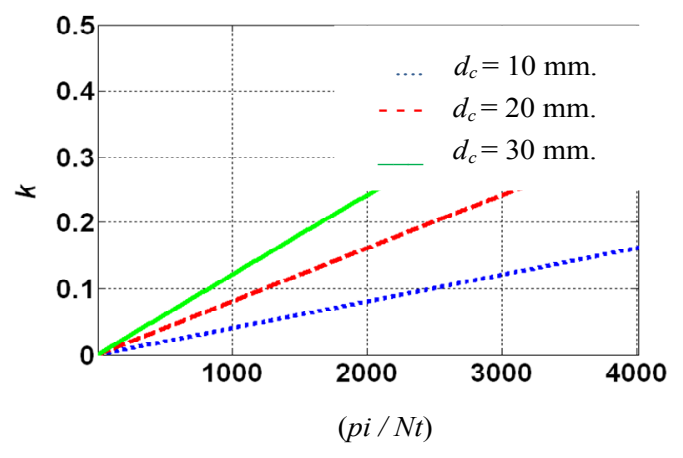

Figure 10. $k$ vs $(p i / N t)$.

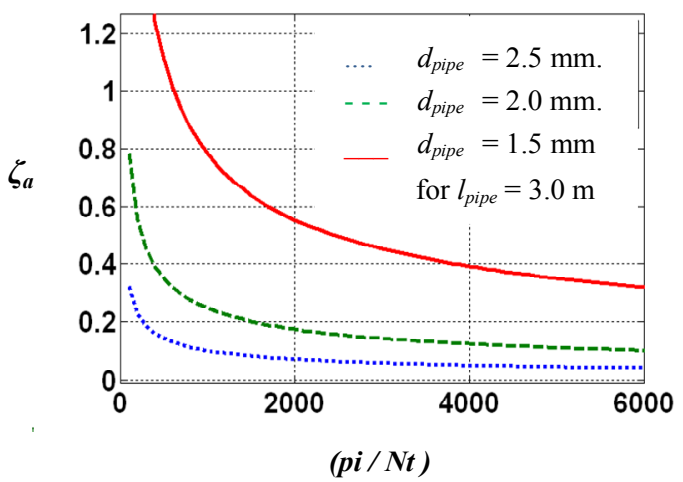

Figure 11. $\zeta_{a} v s(p i / N t)$.

\subsection{Air Pressure Control}

A computer interfacing system containing the closed loop air pressure control system with a set of two LVDTs to sense the main mass displacement $x_{2}(t)$ and base excitation $u(t)$ has been developed. The ratio (pi/Nt) plays an important role in controlling the air damping ratio $\zeta_{a}$ in the system. The appropriate value of the ratio $(p i / N t)$, depending on the value of $\zeta_{a}$ desired in the system can be set by controlling the value of operating air pressure $p i$ for a given value of the ratio $N t=\left(v_{t} / v_{c}\right)$ or keeping the air pressure in the system at atmospheric pressure and adjusting the value of $N t$ by adjusting the tank volume $v_{t}$.

\section{Experimental Analyses}

\subsection{Experimental Curves for Motion Transmissibility Mt2 vs Frequency Ratio $\lambda$}

Using the experimental setup (shown in Figure 9 and Plate 1) and by setting the appropriate values of the air spring rate ratio $k$ and the air damping ratio $\zeta_{a}$, the experimental plots of Mt2 vs $\lambda$ have been obtained for the following cases

1) With $\mu=1.5, \zeta_{1}=0.133, \zeta_{2}=0$ and without air damper.(Refer Figure 12 and Table 10 ).

2) With $\mu=1.0, \zeta_{1}=0.133, \zeta_{2}=0$ and air damper, with $k=0.423$ and $\zeta_{a}=0.1326$ (Refer Figure 13 and Table 11)

3) With $\mu=1.5, \zeta_{1}=0.133, \zeta_{2}=0$ and air damper, with $k=0.423$ and $\zeta_{a}=0.1326$ (Refer Figure 14 and Table 11).

\subsection{Experimental Curves Mt2 vs $\lambda$ for Using Optimal Values of Air Damping Ratio $\zeta_{a o p t}$}

Table 12 shows the theoretical and experimental peak values of motion transmissibility Mt2 at resonant frequency with the air damper set for the optimal air damping ratio $\zeta_{\text {aopt }}: k=0.1$ with $\zeta_{\text {aopt }}=0.53$ and $k=0.4$ with $\zeta_{\text {aopt }}=0.68$. The experimental results have been shown in Figure 15 and Figure 16.

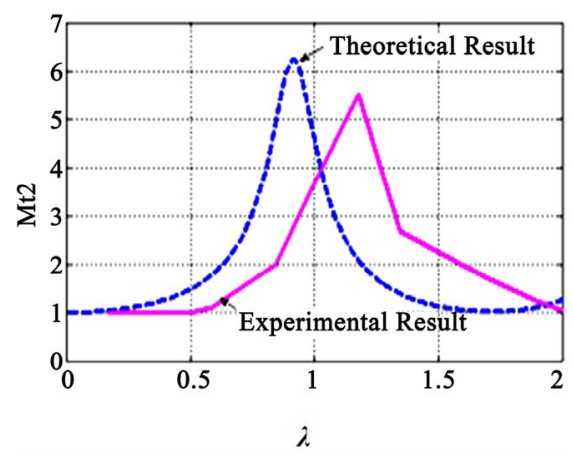

Figure 12. Mt1 vs $\lambda$ for Case 6.1 (i). 
Table 10. Peak values of Mt2 for Case 6.1 (i).

\begin{tabular}{cccc} 
Peak Values of Mt2 & Theoretical Results & Experimental Results \\
\hline $\begin{array}{c}1^{\text {st }} \\
\text { peak }\end{array}$ & Mt2 & 6.235 & 5.50 \\
& $\lambda$ & 0.92 & 1.179
\end{tabular}

Figure No. 12

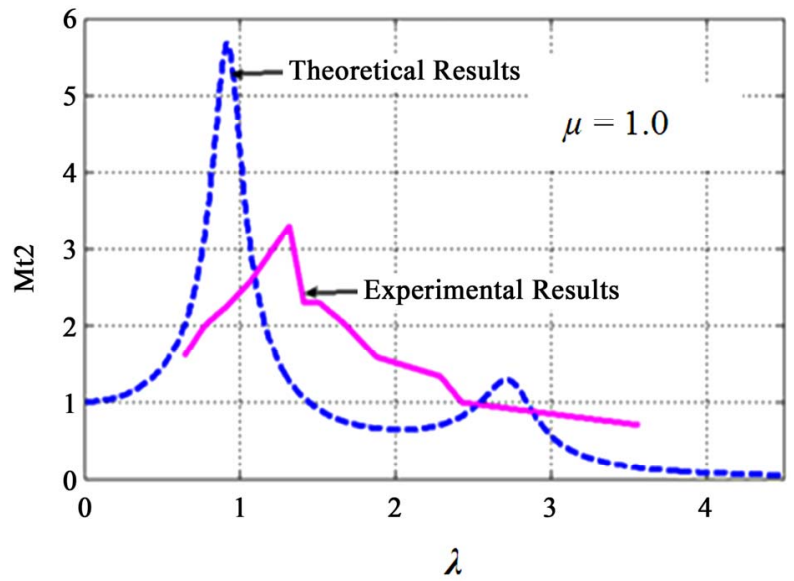

Figure 13. Mt2 vs $\lambda$ for 6.1 (ii), $\mu=1.0, k=0.423$ and $\zeta_{a}=$ 0.1326 .

Table 11. Peak values of Mt2 for the Case 6.1 (ii) and for the Case 6.1 (iii) with $\zeta_{1}=\mathbf{0 . 1 3 3}, \zeta_{2}=\mathbf{0 . 0}$.

\begin{tabular}{|c|c|c|c|c|c|}
\hline \multirow{2}{*}{\multicolumn{2}{|c|}{$\begin{array}{l}\text { Peak Values } \\
\text { of Mt2 }\end{array}$}} & \multicolumn{2}{|c|}{$\begin{array}{c}\mu=1.0, k=0.423 \text { and } \\
\zeta_{a}=0.1326\end{array}$} & \multicolumn{2}{|c|}{$\begin{array}{c}\mu=1.5, k=0.423 \text { and } \\
\zeta_{a}=0.1326\end{array}$} \\
\hline & & $\begin{array}{l}\text { Theoretical } \\
\text { Values }\end{array}$ & $\begin{array}{c}\text { Experimental } \\
\text { Values }\end{array}$ & $\begin{array}{c}\text { Theoretical } \\
\text { Values }\end{array}$ & $\begin{array}{c}\text { Experimental } \\
\text { Values }\end{array}$ \\
\hline \multirow{2}{*}{$1^{\text {st }}$ peak } & $\mathrm{Mt} 2$ & 5.689 & 3.33 & 6.13 & 3.33 \\
\hline & $\lambda$ & 0.92 & 1.35 & 0.92 & 1.32 \\
\hline \multicolumn{2}{|c|}{ Figure No. } & \multicolumn{2}{|r|}{13} & \multicolumn{2}{|c|}{14} \\
\hline
\end{tabular}

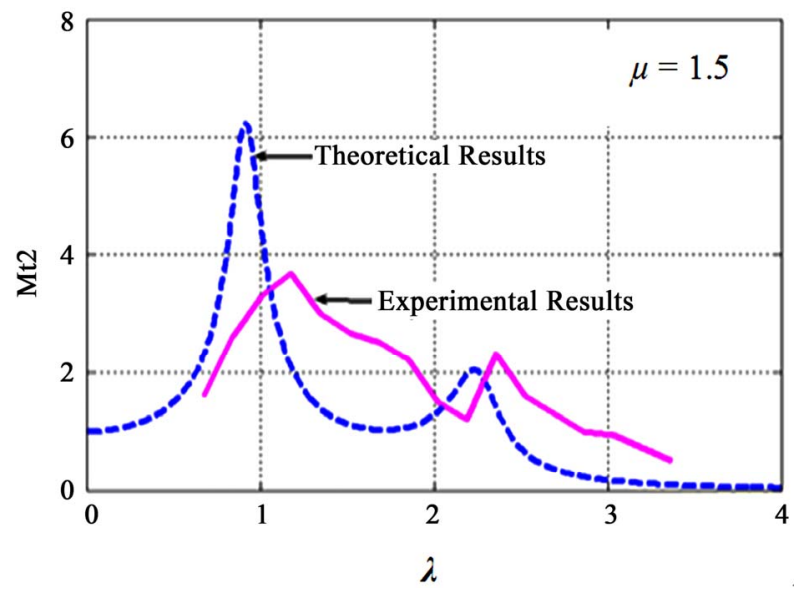

Figure 14. Mt2 vs $\lambda$ for 6.1 (iii), $\mu=1.5, k=0.423$ and $\zeta_{a}=$ 0.1326 .
Table 12. Peak values of Mt2 with optimal valve of optimal air damping ratio $\zeta_{a o p t}$ with $\mu=1.5, \zeta_{1}=0.133, \zeta_{2}=0.0$.

\begin{tabular}{|c|c|c|c|c|c|}
\hline \multirow{2}{*}{\multicolumn{2}{|c|}{$\begin{array}{c}\text { Peak Values } \\
\text { of Mt2 }\end{array}$}} & $\begin{array}{c}\text { Theoretical } \\
\text { Values }\end{array}$ & $\begin{array}{c}\text { Experimental } \\
\text { Values }\end{array}$ & $\begin{array}{c}\text { Theoretical } \\
\text { Values }\end{array}$ & $\begin{array}{c}\text { Experimental } \\
\text { Values }\end{array}$ \\
\hline & & \multicolumn{2}{|c|}{$k=0.1, \zeta_{\text {aopt }}=0.53$} & \multicolumn{2}{|c|}{$k=0.4, \zeta_{\text {aopt }}=0.68$} \\
\hline \multirow{2}{*}{$1^{\text {st }}$ peak } & Mt2 & 2.535 & 1.74 & 1.623 & 1.5 \\
\hline & $\lambda$ & 1.03 & 1.0 & 1.19 & 1.48 \\
\hline \multicolumn{2}{|c|}{ Figure No. } & \multicolumn{2}{|r|}{15} & \multicolumn{2}{|c|}{16} \\
\hline
\end{tabular}

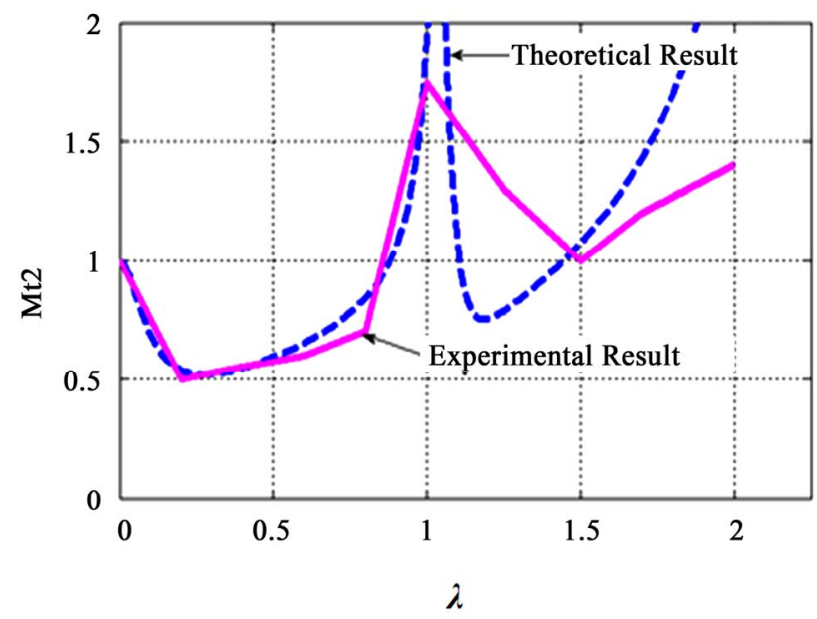

Figure 15. Mt2 vs $\lambda$. For $\mu=1.5, \zeta_{1}=0.133, k=0.1, \zeta_{\text {aopt }}=0.53$.

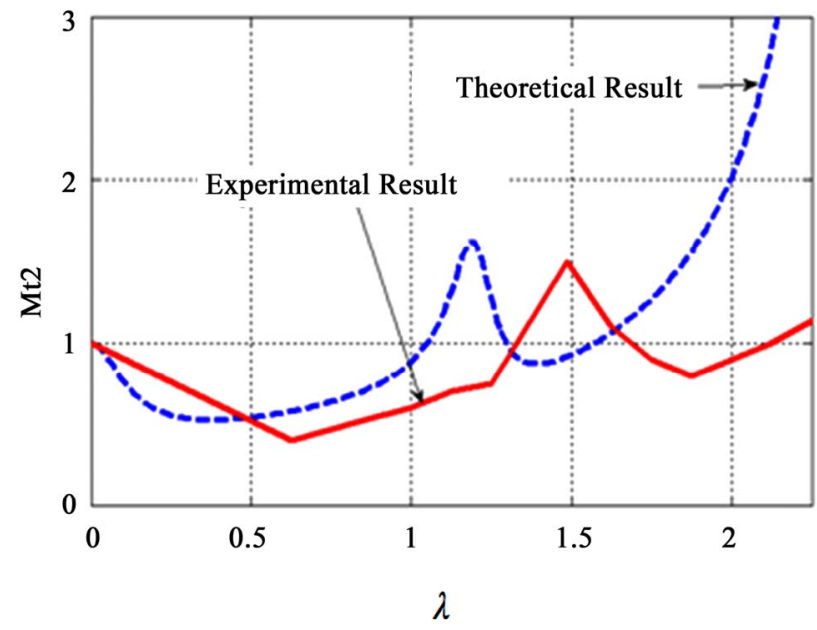

Figure 16. Mt2 vs $\lambda . \mu=1.5, \zeta_{1}=0.133, k=0.4, \zeta_{\text {aopt }}=0.68$.

\section{Conclusions}

In this paper, the effect of mass ratio and the air damper characteristics on the resonant response of an air damped 2DOF vibrating system representing an air damped dynamic vibration absorber model have been studied with the air damper modeled as a Maxwell type. There is no substantial change in the value of Mt2 with the increase 
in the value of mass ratio $\mu$. However, with the increase in the value of the air spring rate ratio $k$ there is a considerable increase in the value of the Mt2 at the resonant frequency where the air damper is modeled as a Maxwell type. It is seen that, with the increase in the value of the air damping ratio $\zeta_{a}$ there is a considerable decrease in the value of the Mt2 at the resonant frequency where the air damper is modeled as a Maxwell type. Further it is seen that as the value of the air spring rate ratio $k$ increases, the value of the optimum value $\zeta_{\text {aopt }}$ of the air damping ratio $\zeta_{a}$ increases with increase in the value of motion transmissibility Mt2. It is also observed that there is a considerable reduction in the value of $\zeta_{\text {aopt }}$ with the increase in the value of the mass ratio $\mu$, in the range $\mu=$ 2.5 to $\mu=5.0$. An experimental setup has been developed with an appropriate air pressure control system. A cylinder-piston and air-tank type air damper has been designed and developed to obtain the desired value of the air damping ratio $\zeta_{a}$ from the air damper. From the results of the experimental analysis shown in Figure 13 and Figure 14, it is seen that the experimental peak values of Mt2 are close to the corresponding theoretical peak values of Mt 2 obtained from the theoretical analysis where the air damper is modeled as a Maxwell type. From the Figure $\mathbf{1 5}$ and Figure 16, it is seen that the theoretical and experimental values of $\mathrm{Mt} 2$ for $\zeta_{\text {aopt }}=$ 0.53 with $k=0.1$ and $\zeta_{\text {aopt }}=0.68$ with $k=0.40$ are in good agreement.

From the theoretical and experimental investigations carried out, it is seen that the addition of the air damping in the absorber system $\left(m_{l}, k_{l}\right)$ improves substantially the motion transmissibility characteristics of the main mass of the 2DOF dynamic vibration absorber model over a range of excitation frequencies in the region of resonance.

\section{Acknowledgements}

The first author Prof. R.G.Todkar acknowledges with thanks the authorities of P.V.P.Institute of Technology, Budhgaon, Dist. SANGLI (Maharashtra) INDIA 416304 for their support and encouragement during the period of this work.

\section{References}

[1] R. A. Williams, "Electronically Controlled Automotive Suspension Systems," Computing and Control Engineering Journal, Vol. 5, No. 3, 1994, pp. 143-148. doi:10.1049/cce: 19940310

[2] T. Asami and Nishihara, "Analytical and Experimental Evaluation of an Air Damped Dynamic Vibration Absorber: Design Optimizations of the Three-Element Type Model," Transaction of the ASME, Vol. 121, 1999, pp. 334-342.

[3] R. D. Cavanaugh, "Hand Book of Shock and Vibration," Air Suspension Systems and Servo-controlled Isolation Systems, Chapter 33, pp. 1-26.

[4] R. G. Todkar and S. G. Joshi, "Some Studies on Transmissibility Characteristics of a 2DOF Pneumatic Semiactive Suspension System", Proceedings of International Conference on Recent Trends in Mechanical Engineering, Ujjain Engineering College, Ujjain, 4-6 October 2007, pp. 19-28.

[5] P. Srinivasan, "Mechanical Vibration Analysis," Tata Mc-Hill Publishing Co., New Delhi, 1990. 


\section{Nomenclature}

$k_{1} \quad$ stiffness of spring for absorber mass

$k_{2} \quad$ stiffness of spring for main mass

$m_{1} \quad$ absorber mass

$m_{2} \quad$ main mass

$\mu \quad$ mass ratio $=\left(m_{2} / m_{1}\right)$

$w_{1} \quad\left(k_{1} / m_{1}\right)^{1 / 2}$

$w_{2} \quad\left(k_{2} / m_{2}\right)^{1 / 2}$

$v$ natural frequency ratio $=\left(w_{2} / w_{1}\right)$

$\zeta_{1} \quad$ system damping ratio for main mass system

$\zeta_{2}$ system damping ratio for auxikary mass system

$w$ applied frequency

$\lambda \quad$ frequency ratio $=\left(w / w_{1}\right)$

$d_{p} \quad$ piston diameter

$d_{c} \quad$ cylinder bore

$l_{p} \quad$ length of the piston

$h_{p}$ height of piston from bottom of the cylinder $d_{\text {pipe }}$ inside diameter of the capillary pipe

$l_{\text {pipe }}$ length of the capillary pipe

$\mu_{o} \quad$ viscosity of air

$n \quad$ index of expansion of the air

$k_{a} \quad$ stiffness of air spring

$k \quad$ spring rate ratio $=\left(k_{a} / k_{1}\right)$

$w_{a} \quad\left(k_{a} / m_{1}\right)^{1 / 2}$

$c_{a} \quad$ coefficient of viscous damping of the air damper

$\zeta_{a} \quad$ damping ratio provided by the air spring

$\zeta_{\text {aopt }}$ optimal value of air damping ratio

$u(t)$ base excitation

$x_{1}(t)$ dynamic displacement response auxiliary mass $m_{1}$

$x_{2}(t)$ dynamic displacement response of main mass $m_{2}$

Mt1 motion transmissibility of the auxiliary mass $m_{1}$

Mt2 motion transmissibility of the main mass $m_{2}$ 